\title{
Editorial: Shared Societies: A new approach to planetary conviventia
}

\author{
STEFANO PRATO
}

The modern conservative is engaged in one of man's oldest exercises in moral philosophy; that is, the search for a superior moral justification for selfishness (John K. Galbraith)

If a man does not keep pace with his companions, perhaps it is because he hears a different drummer. Let each man march to his own rhythm, however measured, or far away (H. D. Thoreau)

This issue of Development explores the concept of 'Shared Societies' developed by the Club de Madrid to inspire a notion of society where all individuals and constituent groups hold status as equally contributing participants, free to express their differences while integrating their voices within the broader population.

Unfortunately, the world around us does not seem to share these aspirations. The tragedies of Ukraine, Gaza, Iraq, Syria, Libya, Nigeria, to name but some of the most recent headline-hogging places, suggest otherwise. A lethal cocktail of hate for diversity, quest for power and greed appears to be a stronger driver than the aspiration for peace, understanding and conviviality. Beyond these macroscopic conflicts, it is even more disheartening to experience the progressive erosion of the social foundations of many of our societies and the globalization of loneliness in a world overwhelmed by communication revolutions and new forms of instant media. Despite the vast information exposure about human suffering, something akin to 'hydro-repellence' seems to be in the making as we witness growing indifference to the depth of the tragedies that surround us. Interestingly, weaker social foundations and decreasing empathy are related to a significant reduction of the societal resilience against shocks precisely when unpredictability becomes the norm with such a higher frequency of extraordinary climate events, social turmoil and other unexpected crises.

In the constant tension between reality and aspirations, the asynchrony between the development debate and the world around it does not represent an element of novelty. However, the ongoing discussions on the post-2015 development agenda are now pushing such an asynchrony to an entirely new level of ambition. The need to claim success in the implementation of the Millennium Development Goals (MDGs) is pushing the development industry towards an inappropriate celebration of poverty reduction and social progress against a world that continues to be plagued with violence, hunger and destitution. This is not to deny that progress took place in many social development areas but one cannot be blind to the inadequacy of the benchmarking parameters that are 
being used - the target that everyone should have an income of at least US\$ 1.25 a day being a perfect example despite the rivers of justifications that conventional economists can provide as to its appropriateness. The MDG attribution question also raises other issues as the supposed halving of world extreme poverty was largely dependent on China's progress, something the MDG framework can hardly claim to have influenced. Beyond all this, the main concern is that the global development agenda has not managed to influence the main global drivers of exclusion, inequity and unsustainability, and rather facilitated a global-scale social bribery to ensure that some few crumbs could fall off the table of the wealthy to keep the poor and marginalized afloat and pacified. Indeed a noble goal, but too instrumental in ensuring that the current dynamics of global accumulation proceed undisturbed by excessive social strain and unrest.

The news is that this bribery does not seem to work anymore. Global protests are rising as the profile of growing inequalities shake social contracts around the globe. Nevertheless, the lack of proper diagnostics and critical assessment by the development establishment is fuelling high rhetoric. We are therefore witnessing the emergence of a new global development agenda that is once again more concerned with regulating the local rather than the global, and is therefore pushing forward the homogenizing concept of modernity that has progressively conquered our societies over the past decades regardless of its failures and the tensions they have generated.

Are there reasons to be hopeful? Indeed, there are. Many social movements, local communities, civil society organizations and solidarity initiatives promote new ethical foundations for the cohabitation of diversity, new forms of conviviality, alternative economic frameworks, new agencies for the provision of social services, new ecologies based on surpassing anthropocentrism in favour of biocentrism, and rights-based models of governance centred on citizens' agency and pluralism. Unfortunately, these initiatives remain peripheral to the mainstream modernity project and can, therefore, be more easily classified as experiments of human resistance than real seeds
However, some signs of coalescence of these development alternatives into a new vision of humanity are emerging. In this context, the Shared Societies proposition is consistent and aligned with the calls for BuenVivir and Planetary Conviventia - ideas that initially emerged from the practices and visions of the indigenous people of the Andean Region of Latin America and which were further elaborated upon by social movements, progressive civil society organizations, and radical thinkers and activists.

The vision that emerges is inspiring although it clashes significantly with some major features of current modernity that our societies are struggling with and that are profoundly altering our human experience. Interestingly, these are increasingly manifesting themselves across the globe without the conventional distinctions across developed and developing countries. Another example of the emerging need for a universal development agenda that can inspire a new ethic for global citizenship based on the respect of diversity and the appreciation of global conviviality. However, the following major obstacles seem to be in the way and would need to find proper responses for our societies to be truly engaged in alternative paths towards harmony and sustainability.

\section{The ossification of fear and the priming of violence}

Violence continues to plague our societies at many different levels. From the domestic space up through to national politics, violence seems to be a key feature of the modernity project and the current private and public responses are increasingly directed towards gates, fences, body scans, surveillance and armed security forces. The response to violence or the threat of it seems to generate further insecurity and sediment a 'fear of the other' in the depth of our minds. From the evolutionary standpoint, fear is a neural circuit that aims to keep the organism alive in dangerous situations. The brain's response to fear is therefore almost entirely automatic. We do not control the chain reactions triggered from danger and stress, as these are hard-wired in our biological survival response mechanisms. On the contrary, 
hope involves a slow process that requires the active engagement of our conscious mind. In a nutshell, fear is much quicker and effective than hope in taking over the control seat of our behaviour.

Whether we live in situations of open conflict, we experience domestic violence or we are afraid for our personal security or that of our properties, it seems societies are increasingly driven by fear rather than hope. On top of this, very few seem to be concerned with the fact that we, as well as our children, are constantly 'primed' by violence through movies, news, social media and videogames. The verb 'to kill' is happily used in colloquial expressions with little importance attached. You hear children use it with complete indifference. Not to mention, the continued and increasing commodification of human bodies particularly the female one. It is difficult not to correlate these forms of 'mental priming' with the atrocious episodes of domestic violence that many supposedly modern societies are increasingly experiencing. Furthermore, the production and trading of arms - from weapons of mass destruction to small arms - knows no crises.

The combination of fear, priming of violence and availability of arms composes an equation that inevitably leads to its mathematical results. We see them all around us. In the animal world, intraspecies violence is largely limited to defensive purposes and rarely pushed to the lethal stage. The preservation of life is deeply coded in social structures and behavioural models based on 'calming signals'. The human project seems to have pushed violence far beyond its biological determinants and recoded the preservation of life in terms of the exclusive protection of the 'self'. The consequence is the excessive emphasis placed on protecting individuals and families from the threat of violence rather than creating a culture of peace where people are interacting non-violently and are managing their conflict positively - with respectful attention to the legitimate needs and interest of all concerned. Johan Galtung would define this as seeking negative peace (absence of violence) versus building positive peace (culture of peace). Some would see these two concepts as sequential phases although means and ends are closely interconnected, as per the eloquent words of Martin Luther King:

They are talking about peace as a distant goal, as an end we seek, but one day we must come to see that peace is not merely a distant goal we seek, but that it is a means by which we arrive at that goal. We must pursue peaceful ends through peaceful means. All of this is saying that, in the final analysis, means and ends must cohere because the end is preexistent in the means, and ultimately destructive means cannot bring about constructive ends.

It is therefore encouraging to hear the many governmental and non-governmental voices that continue to stress the need for greater focus on peace as one of the key pillars of the new post2015 development agenda. However, the current negotiations seem to make every possible attempt to water down these aspirations with the argument of either protecting national sovereignty or maintaining the international power structures that emerged out of World War II.

\section{The breaking down of social foundations and the progressive physical isolation of human existence}

Violence and insecurity are also consistent with the progressing breaking down of human relations as well as their social and ecological foundations. Many voices increasingly highlight that modernity seems be somehow associated with loneliness, helplessness, emotional distress, depression and anxiety. Recently released data from the World Heath Organization (WHO) indicates that over 800,000 people die due to suicide every year and there are many more who attempt it. Suicide was the second leading cause of death among 15-29 year olds globally in 2012. In this respect, two interesting dimensions of modernity might require further investigation: the explosion of virtual relations and the booming attention and care for house pets.

A significant share of social relations now take virtual means up to the extreme of young people refusing human interaction. In Japan, the term 'hikikomori' is used to describe those young people who withdraw from society and decide to hide in 
their rooms paralyzed by profound social fears (Tateno et al., 2012). A 2010 survey for the Japanese Cabinet Office resulted in a shocking figure of 700,000 affected young people. Since sufferers are by definition hidden away, some psychologists place the figure at an even higher level, maybe around 1 million. These young people are often from middle-class families, tend to be male, and the average age for their withdrawal is 15 . It should also be noted that, within Japanese society, the number of single people has reached a record high. A 2011 survey found that 61 percent of unmarried men and 49 percent of women aged 18-34 were not in any kind of romantic relationship, a rise of almost 10 percent from five years earlier. Another study found that a third of people under 30 had never dated at all while a survey by the Japan Family Planning Association found that 45 percent of women aged 16-24 'were not interested in or despised sexual contact'. More than a quarter of men felt the same way.

When assessing the social determinants and implications of these 'shut-in youth', many initially framed the problem in terms of the peculiar connotations of Japanese society. However, there is growing evidence that this alarming phenomenon is also spreading to Europe and further exacerbates the social isolation that is caused by illness, drug abuse and, unfortunately, aging.

It is interesting to correlate such growing social withdrawal with the increased importance of pets in people's lives. While some like to believe this to be the expression of a profound desire to reconnect with our ecology and nature, many humanpet relations seem to be somehow misdirected by loneliness and social alienation. This highlights a mismatch between the supply and demand of care: in societies where care needs are inadequately addressed (children, elderly, vulnerable groups) there seems to be an excess of care directed towards cats, dogs and other household pets. Increasingly, the emerging middle classes in developing countries seem to be leap-frogging into similar patterns with growing sections of supermarkets devoted to pet food and toys even in countries where hunger and destitution remain a daily reality for large shares of
It is equally interesting to assess the growing political power of animal rights groups versus human rights ones in Europe and United States. Recent decisions by several multinational corporations to adopt more stringent animal welfare requirements along their supply chain in response to pressure by animal rights groups raise profound ethical concerns when compared with the strong lobbying by similar corporations - if not the same ones - against the establishment of an open-ended intergovernmental working group that is mandated with elaborating an international legally binding instrument to regulate, in international human rights law, the activities of transnational corporations and other business enterprises with regards to human rights violations.

Many would eloquently argue that the development agenda should not be concerned with such issues. It is however interesting to correlate the weakening of the social foundations with the profoundly individualistic human development agenda currently exposed by many development agencies. There has been and continues to be a significant underestimation of the importance of social capital in advancing the human and social development agenda.

Hanifan (1879-1932) first referred to social capital as 'those tangible assets [that] count for most in the daily lives of people: namely goodwill, fellowship, sympathy, and social intercourse among the individuals and families who make up a social unit' (Hanifan, 1916). More recently, the term has been referred to the institutions, relationships and norms that shape the quality and quantity of a society's social interactions. Even the World Bank (WB) highlights increasing evidence that social cohesion is critical for societies to prosper economically and for development to be sustainable. Quoting from the WB website: 'social capital is not just the sum of the institutions that underpin a society - it is the glue that holds them together.. ${ }^{1}$ Others refer to social capital as the collective value of all 'social networks' and the inclinations that arise from these networks to do things for each other (norms of reciprocity).

The importance of building social capital seems to escape the narrative and framework of the new development agenda and may as well be a 
contributing factor to the progressive emergence of 'economies without societies' in many developing countries. One of the consequence of this frame of mind is the narrow interpretation of civil society as a primary service delivery agent rather than a vehicle for civic agency and a critical determinant of the social glue that keeps societies together. Many would suggest that such an interpretation was also functional to the domestication of the structure of dissent in many new democracies. There is, therefore, urgent need to engage with the final stages of negotiation on the new agenda to ensure greater recognition that societies are not merely the sums of their individual members and critical consideration to the social fabric of public benefit institutions and other forms of civic association.

\section{The persistence of patriarchal structures and the crises of care}

Violence is 'gendered'. It is a tautology that the perpetrators of violence are primarily male and their victims often tend to be women and children. Despite the progress in advancing women's rights, patriarchal structures seem to persist more than we would have expected. The structures of modern society, its economy and governance, remain encoded into a particular algorithm of gender roles and therefore misrepresent and undervalue the social foundations and care needs that ensure the smooth transitions among generations and lubricate social relations. While rhetoric flies high, a serious gender dialogue and rethinking of gender roles within societies is yet to start, sometimes even in those societies where women's rights are more secure and some degree of empowerment has actually taken place. Indeed, the resurgence of right-wing extremism and conservative values is often trying to push the clock back and even reverse earlier achievements. In this context, it also remains unclear how such gender dialogue can be promoted given the lack of corresponding structures on men's side to the organized women's movement and the limited leeway this discourse has within the educational system. Interestingly, the progress in women's economic empowerment through formal employment is sometimes contributing to the social stratification of women, by establishing a new class of care workers whose own care needs are profoundly frustrated. This confirms once again that women carry the burden of the adjustment rather than it being confronted as a societal problem.

The new development agenda seems to be extremely upfront with the critical importance of gender equality. Many indeed agree that this is probably the single most important transformative shift with profound cascade effects in the promotion of a culture of peace and non-violence and the nurturing of renewed social foundations of our societies. However, it is important not to confuse rhetoric with the reality of the vast majority of women that continue to struggle in their daily lives with oppression, violence and marginalization. The recent backslash against sexual and reproductive rights have also reminded all progressive forces that conservative values remain alive and kicking. More than this, it is essential to recognize that patriarchal structures are deep in our minds (both those of women and men) and frame the way we think and see reality despite our best intentions. Reprogramming our underlying mental structures is by far our greatest challenge.

\section{Rising inequalities and the nexus between poverty and prosperity}

Maria Fernandes, 32, of Newark, NJ, worked four jobs, including two at different Dunkin' Donuts stores. In between work, she would often park in public lots and catch up on sleep. She kept a can of gasoline in her car because she had occasionally run out of gas in the past during her job commutes. While taking a nap in between jobs, she died from inhaling a fatal mixture of carbon monoxide from her car, which was running, and the can of gasoline that had spilled open in the back of her car.

Maria's life and death expose another distinctive feature of modern societies: the rise of inequalities across economic, social, political and intergenerational domains irrespectively of the conventional distinction between the Global North and South. This is probably one of the distinctive framing issues of our times and many voices are loudly advocating for the strong focus on equity in the 
next development agenda. Nonetheless, reconnecting people and planet with our economies and societies is no easy task, as it requires profound transformations in the social, economic and political domains.

In this respect, there is an often-malicious attempt to interchangeably use the terms 'inclusion' and 'equity', with the inclusive growth narrative being a perfect example of this policy inclination, - one that masks the intent to leave fundamentally unchanged the terms of inclusion with very uneven power relations and inequitable economic and social outcomes. This state of affairs highlights the lack of due consideration for the political economy of inequalities: the latter are being often referred to as some sort of natural outcome which requires mitigation rather than the result of deliberate policies of exclusion and exploitation. Income inequalities, often flagged as a critical dimension of the equation, represent only one of the elements of a much larger puzzle that sees the growing concentration of wealth, resources and political power in few hands. The search for equity inevitably involves profound changes in power relations that current power holders have limited interest in stewarding. Hence, the complexity of this agenda and the overt and covert attempts to frame it in more friendly terms for those in power. Indeed, the inequality discourse is profoundly different from the past pro-poor focus as it exposes the close nexus between poverty and prosperity and highlights the need for policy renewal at both ends of the economic and social distribution. It involves an agenda on the rich rather than an exclusive focus on the poor.

Interestingly, it is the first time in modern history that one common concern appears to be so deeply shared by the poor and marginalized as well as struggling middle classes across the entire globe. Some identify in the proliferation of 'occupytype' movements and the rise in global protests the early signs of what might possibly become a new global class warfare, something that has the potential of profoundly destabilizing our societies and economies and maybe radically transforming them. Indeed, there is something about inequalities - some sort of a deeply embedded reaction to generate an even stronger emotional drive than poverty per se.

It is also worth highlighting the close interdependence between the rise of inequalities and the other previously mentioned dimensions. Many studies have highlighted the correlation between vertical inequalities and criminality as well as that between horizontal inequalities and social unrest, particularly in multiethic nations. The spike in inequalities could therefore be regarding as one of the structural determinants of violence. Secondly, the weakening of social foundations actually facilitates the social acceptance of inequalities and decreases the moral pressure on those that are better off.

\section{The broken relations with central power and the quest for a new ecology}

Violence, social fragmentation, patriarchal structures and inequalities seem to be finding a home rather than resolution in many highly centralized states and the unsustainable exploitation of the ecology that often characterizes them. This is probably the reason why many voices call for urgent transitions towards greater democratic participation and subsidiarity of state structures for local communities to be re-empowered with the direct control over their ecology and resources. Against such calls for power to be brought closer to the people and their communities, the new agenda seems to consolidate the increasingly outdated notion of the Westphalian nation state with very limited consideration for the centrality of active citizenship and real participation.

Rather than limiting the democratic space, the development agenda should encourage societies to revisit the implicit and lifelong assumptions made around their respective social contracts, particularly given their challenges, the impact of skewed and uneven growth, and extensive emergence of what one might call 'negative politics', which tends to reward elites at the expense of majorities and reproduces itself in an incestuous manner. Furthermore, such a new agenda should also stimulate societies to create open and honest spaces to engage with the increasingly challenging interface between cultural ideologies (Islam, the 
Confucian model, the Judeo-Christian or Western one, as well as others) rather than overtly or covertly sheltering if not augmenting the 'battle for the last soul'. The fact that there is little space for dialogue or accommodation is perhaps what is also providing increasing space for extremists to pursue their ideals through unacceptable means.

The need to revisit social contracts is even more urgent whenever the spectrum of national diversity includes social groups that reject modernity or resist the homogenizing cultural forces that drive it. In this respect, even the progress made in some countries to integrate minorities and provide for local autonomies is often unsatisfactory if equated to higher concepts of cohabitation and conviviality. Greater spaces for the experimentation of new forms of devolved authority and community self-determination are required to advance the notion of truly shared societies. As
Max Planck said, 'Experiments are the only means of knowledge at our disposal. The rest is poetry and imagination'.

In the context of all these challenges, the aspirations for harmonious, just and convivial societies, which are promoted by conceptual frameworks such as those of Shared Societies and BuenVivir, convey vital rays of light into the somehow gloomy prospects of our post-modern societies. The challenge remains how to find a path towards such new visions for humanity, being aware that it is likely not to be linear and nicely organized. The former Burkinabe President, the late Thomas Sankara once said: 'You cannot carry out fundamental change without a certain amount of madness. It comes through non-conformity, the courage to turn your back on the old formulae and to invent the future'.

\section{Note}

1 http://web.worldbank.org/WBSITE/EXTERNAL/TOPICS/EXTSOCIALDEVELOPMENT/EXTTSOCIALCAPITAL/0, contentMDK:20185164 menuPK:418217 pagePK:148956 piPK:216618 theSitePK:401015,00.html.

\section{References}

Hanifan, Lyda Judson (1916) Evening Classes for West Virginia Elementary Schools. Charleston, WV: Department of Free Schools.

Tateno, Masaru, Tae Woo Park, Takahiro A Kato, Wakako Umene-Nakano and Toshikazu Saito (2012) 'Hikikomori as a Possible Clinical Term in Psychiatry: A questionnaire survey', BMC Psychiatry 12(1): 169.

WHO (2012) Mental health, Suicide date, http://www.who.int/mental_health/prevention/suicide/suicideprevent/en/, accessed 8 September 2014. 